\title{
From plague to MERS: coordinating Australia's response to emerging infectious diseases
}

\section{Jenny Firman a,b, Stephanie A Williams ${ }^{a}$ and Chris Baggoleya}

a Office of Health Protection, Australian Government Department of Health, Canberra, ACT

b Corresponding author: jenny.firman@health.gov.au

\section{Article history}

Publication date: December 2016

Citation: Firman J, Williams SA, Baggoley C. From plague to MERS: coordinating Australia's response to emerging infectious diseases. Public Health Res Pract. 2016;26(5):e2651654. doi: http://dx.doi. org/10.17061/phrp2651654

\section{Key points}

- Emerging infectious diseases present ongoing public health risks in Australia and internationally

- Australia has coordinated national response arrangements to detect, assess and respond to emerging infectious diseases

- Communication, surveillance, laboratory testing and typing, and public health management of cases and contacts are some of the critical elements of a public health response described in this article

- A flexible systematic approach is vital for effective and coordinated future public health responses

\section{Abstract}

Rapid international travel times and the arrival of new and unexpected infectious disease threats have demonstrated that, for effective communicable disease control, Australia's response needs to be flexible and coordinated. This paper summarises how our public health and clinical systems would respond to a case of Middle East respiratory syndrome coronavirus and our responsibility under the International Health Regulations to notify the World Health Organization (WHO). It also describes the processes undertaken by WHO when it declares that a disease outbreak is a Public Health Emergency of International Concern.

Australia has robust communicable disease response systems, tested by new threats for many years, which are under constant review and improvement.

\section{Introduction}

When Australia was first settled by Western cultures, quarantine was the main method of protecting the community against emerging infectious diseases. In 1805, the whaling ship Richard and Mary was the first ship to be officially quarantined, the crew members suspected of being "infected with a dangerous fever" following news of a yellow fever epidemic in the State of New York. ${ }^{1}$ This method of keeping some diseases from reaching Australian shores was reasonably effective, because the long voyage time to Australia usually meant that any incubating disease had declared itself before the vessel arrived and, on arrival, a response usually involved a single jurisdiction managing one ship at a time. But even on such matters, states and territories differed and each had their own Quarantine Act.

As the colony grew and transport times shortened, ships brought new disease threats - a plague outbreak lasting 10 years started in 1900, with sporadic outbreaks in all states except Tasmania. ${ }^{2}$ States and territories called for a consistent approach, leading to the formation of the Federal Quarantine Service. Although this helped to coordinate quarantine measures, the limits of quarantine were soon realised with the arrival of the 1918 influenza pandemic, which was well and truly under way in Australia in 
1919. Returning troops from World War I were unhappily confined at the Sydney Cricket Ground for 2 days of quarantine, but this did little to stop the spread of this lethal pandemic. ${ }^{3}$

If faster shipping times reduced the effectiveness of quarantine for infectious diseases, then this method of quarantine is very limited in the face of international air travel and globalisation. Today, rapid international travel times and ongoing emergence of unexpected threats demonstrates that Australia's response to emerging infectious disease needs to be flexible and coordinated, nationally and internationally.

Our ability to predict where the next emerging infectious disease will come from has been limited. Although the world planned for a potentially catastrophic pandemic of avian influenza, the SARS coronavirus emerged in 2003, leaping from bats to civets to humans, and spread rapidly around the world, costing the global economy an estimated $\$ 40$ billion. ${ }^{4}$ Global pandemic planning continued, but the 2009 influenza pandemic that emerged was milder than expected. The Middle East respiratory syndrome (MERS) coronavirus emerged in 2012 and has caused multiple clusters of infections within healthcare facilities, highlighting the need for good infection control and prevention in these settings. The 2015 MERS outbreak in South Korea affected 186 people, of which $44 \%$ were patients exposed in hospitals, $32.8 \%$ were caregivers and $13.4 \%$ were healthcare personnel. ${ }^{5}$ During the past 2 years, the world has witnessed the devastating Ebola virus disease outbreak in West Africa, and the epidemic spread of the vectorborne Zika virus throughout the Americas. These were all outbreaks that re-emerged in different and unexpected settings with new and, at times, frightening outcomes. Each event has required a nationally coordinated effort to prepare and respond, on top of the daily business of health protection and communicable disease control in Australia.

\section{What would happen if we had an outbreak of MERS coronavirus in}

\section{Australia?}

Imagine if a single MERS coronavirus case attended a conference in Australia, then visited a primary care clinic early in the illness, and then a hospital emergency department before being diagnosed, with contacts dispersing around Australia and internationally. There would be many elements to a coordinated response in Australia; a few critical elements are described here.

\section{Detection and reporting}

MERS is a high-priority notifiable disease requiring rapid public health actions. The response system relies on an astute frontline clinician to consider uncommon infectious diseases such as MERS in patients who have recently travelled overseas, and to be aware of the importance of communicating this to public health authorities.

The doctor who suspects and diagnoses MERS would notify the relevant communicable disease control authority, which is usually the state or territory health department.

The director of communicable disease control in the health department of the affected state or territory would commence immediate public health actions to identify contacts. They would ensure that their relevant chief health officer, the Australian Government Chief Medical Officer and the Communicable Diseases Network Australia (CDNA) were informed.

\section{National coordination}

The CDNA - composed of directors of communicable disease control in each state and territory, and national disease control experts - would meet urgently to review the epidemiology, confirm the public health actions, liaise with the Public Health Laboratory Network to confirm testing capabilities and interpretation, and review the existing advice and guidelines to ensure they are complete and current for this outbreak.

The Australian Health Protection Principal Committee (AHPPC) would meet to coordinate the public health response across Australia. ${ }^{6}$ The AHPPC is chaired by the Australian Government Chief Medical Officer, and includes the chief health officers of all state and territories, as well as representatives from other emergency organisations and the Australian Government Department of Defence. The AHPPC is responsible for overarching national leadership through cross-jurisdictional collaboration on communicable disease incidents of national significance, such as a MERS outbreak.

A whole-of-government approach is part of Australia's response to any new international or domestic communicable disease threat. Relevant sections of government are regularly consulted and participate in response actions. Close communication during a MERS outbreak would seek to ensure that all parts of government understand the outbreak and the likely health and community consequences, caused not only by the disease but also by any response actions.

\section{National public health and clinical guidance}

MERS is a known threat. Although the exact transmission routes are not known, human-to-human transmission in healthcare facilities has occurred in settings where there were inadequate infection prevention and control practices. ${ }^{7}$ In Australia, clinical advice and public health management guidelines already exist, as do infection prevention and control guidelines. ${ }^{8,9}$ These guidelines are intended to support clinicians caring for a MERS case and public health authorities managing any contacts to prevent further spread. 


\section{Public health management: finding and} managing cases and contacts

State and territory departments of health would be responsible for finding and managing domestic contacts, a critical part of the response. The management of MERS contacts seeks to prevent further spread of infection in the community. High-risk contacts of a MERS case would be kept under surveillance for 14 days. This would require daily communication between the contact and state or territory health department, to enable a quick response to early signs of MERS infection, and organise for their transition to a healthcare facility for further assessment and testing, if required.

In addition, detailed liaison with airlines and government authorities would be required to follow up any contacts who may have already travelled to other national and international destinations. If there were people who had attended the same conference as the MERS case and had travelled overseas, the Australian Government - acting as the National Focal Point described by the International Health Regulations (IHR) 2005 - would make every effort to trace these contacts and connect them with public health services in their home countries.

\section{Communicating with clinicians and the healthcare sector}

The Australian Government Department of Health engages in regular communication with clinicians and the healthcare sector through peak bodies, professional colleges and associations, to improve preparedness and response to communicable disease outbreaks.

Even if the MERS outbreak was limited to a few hundred people, information would be provided throughout the Australian health system. The Australian Government Department of Health would disseminate information to front-line clinicians in primary care, emergency departments, hospitals and laboratories through multiple stakeholders, including the Royal Australian College of General Practitioners, the Australian Medical Association, the Australasian College for Emergency Medicine, the College of Intensive Care Medicine, the Royal Australasian College of Physicians, the Australian College of Rural and Remote Medicine, and the GP Roundtable.

\section{Public information and the media}

A MERS case will attract high levels of media attention. This can be very helpful in alerting the public to a new communicable disease threat, but can create unnecessary alarm if more sensational aspects are overemphasised or conflicting advice is reported from individual experts. The National Health Emergency Media Response Network aims to keep the public and media informed during outbreaks by providing consistent and coordinated media and public responses. The
Department of Health, advised by the AHPPC and CDNA, supports development of key messages that can be used and adapted by state and territory health authorities. Communications to the public can be through a range of methods, including online advice, fact sheets, questions and answers, social media and telephone information lines, where these are needed.

\section{Communicating with the World Health Organization}

A MERS case in Australia could meet the criteria set out in Annex 2 of the IHR 2005 - an unusual or unexpected event with a significant risk of international spread (Figure 1). Australia would notify the World Health Organization (WHO) through the National Focal Point in Canberra.

The existing MERS IHR Emergency Committee has met on 10 occasions, with the most recent meeting held on 2 September $2015,{ }^{10}$ where the Committee agreed that MERS still did not constitute a Public Health Emergency of International Concern (PHEIC). A PHEIC is "an extraordinary event which is determined to constitute a public health risk to other states through the international spread of disease and to potentially require a coordinated international response". ${ }^{11}$ The Committee did, however, emphasise the need for: ${ }^{10}$

- Good infection prevention and control in healthcare facilities

- Rapid sharing of health information of public health importance

- Collaboration between animal, agricultural and human health sectors

- A collaborative, whole-of-government response to the challenges posed by MERS.

Australia is a strong supporter of $\mathrm{WHO}$ and the international coordination of communicable disease outbreak response. Australian health officials have been part of the process under the IHR to determine whether a disease poses a PHEIC, most recently for MERS (2013), polio (2014), Ebola virus disease (2014) and Zika virus disease (2016).

\section{Emerging evidence and research}

At the beginning of a communicable disease outbreak, particularly where this involves an emerging infectious disease, there is limited information and evidence. Research can provide answers to questions that are important for communicable disease outbreak response planners; for example, how easily does MERS spread and how severe is MERS in the Australian context? Partnerships between researchers and health policy makers and planners help us to understand and use new sources of surveillance, such as social media, to improve epidemiological information through data linkage, and to harness new technologies such as microbiological genomics to understand and track disease outbreaks. 
The Centre of Research Excellence in Infectious Disease Emergency Response Research, recently announced by the National Health and Medical Research Council, will help support this research.

\section{How does Australia compare with other countries?}

Most Organisation for Economic Co-operation and Development countries have communicable disease control systems that work within their overall structure of government. Australia is similar to countries like Canada in its federal government coordination of national outbreak responses, supported by expert committees, and publication of advice for healthcare professionals, the public and other stakeholders on national health websites. This is in contrast to countries such as the UK and New Zealand, where a single national government assumes outbreak control responsibility, in the absence of state or territory health authorities. However, despite differences in governance, responses generally include

Figure 1. Detecting an unusual or unexpected event with a significant risk of international spread

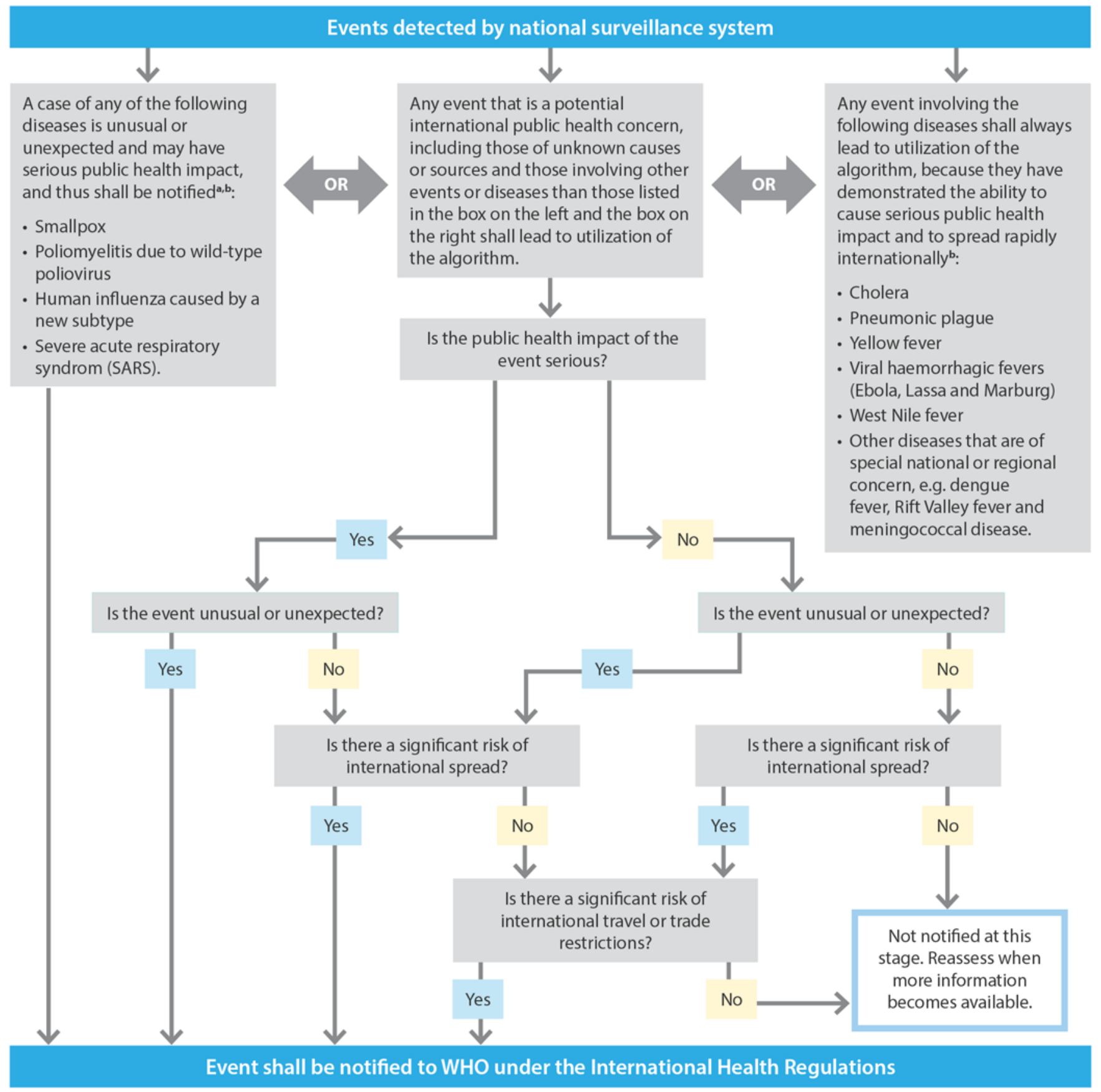

Extracted from Annex 2 of WHO International Health Regulations (2005).

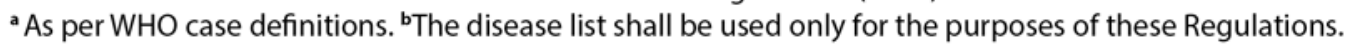


the same public health response measures: surveillance, contact tracing, outbreak investigation, communications, population-based interventions and applied research.

\section{Conclusion}

Through a hypothetical MERS outbreak, we have described some of the critical elements of coordinating a response to emerging infectious diseases in Australia. We have robust communicable disease control systems that have been tested and improved through responses to many communicable disease threats, particularly during the past 15 years. A flexible, systematic approach is vital for effective and coordinated future responses.

\section{Competing interests}

None declared

\section{Author contributions}

JF was the principal author, responsible for the content and organisation of the manuscript. SW and CB provided comment and suggestions.

\section{References}

1. Lewis MJ. The people's health: public health in Australia, 1788-1950. Westport, CT: Greenwood Press, 2003.

2. Department of Health. Fifty years of health: a history of the Commonwealth Department of Health, 19211971. Canberra: Australian Government Publishing Service, 1973.

3. Australian Bureau of Statistics. Canberra: Australian Bureau of Statistics; 2016. Human quarantine. The Australian approach to a world problem; 2012 Nov 23 [cited 2016 Jul 6] [about 8 screens]. Available from: www.abs.gov.au/ausstats/abs@.nsf/featurearticlesbytitle/ F74D29E8BE724723CA2569DE0024ED5C?OpenDocum ent
4. Lee JW, McKibbin WJ. Estimating the global economic costs of SARS. In: Institute of Medicine (US) Forum on Microbial Threats; Knobler S, Mahmoud A, Lemon S, et al., editors. Learning from SARS: preparing for the next disease outbreak: workshop summary. Washington (DC): National Academies Press (US); 2004.

5. Korea Centers for Disease Control and Prevention. Middle East Respiratory Syndrome coronavirus outbreak in the Republic of Korea, 2015. Osong Public Health Res Perspect. 2015;6(4):269-78.

6. Australian Government Department of Health. Canberra: Department of Health; 2016. Health emergency preparedness and response; 2009 Jun 18 [cited 2016 Jun 25] [about 3 screens]. Available from: www. health.gov.au/internet/main/publishing.nsf/Content/healthpubhlth-strateg-bio-index.htm

7. World Health Organization. Geneva: Word Health Organization; 2016. Middle East respiratory syndrome coronavirus (MERS-CoV) fact sheet, 2015 Jun [cited 2015 Jul 6] [about 5 screens]. Available from: www.who. int/mediacentre/factsheets/mers-cov/en/

8. World Health Organization. Middle East respiratory syndrome coronavirus (MERS-CoV). Summary of current situation, literature update and risk assessment. Geneva: WHO; 2015 [cited 2016 Jun 15]. Available from: apps. who.int/iris/bitstream/10665/179184/2/WHO_MERS_ RA_15.1_eng.pdf?ua=

9. Communicable Diseases Network Australia. Middle East respiratory syndrome coronavirus (MERS-CoV). CDNA national guidelines for public health units. Canberra: Australian Government Department of Health; 2015 [cited 2016 Jun 22]. Available from: www.health.gov.au/internet/ main/publishing.nsf/Content/DA7D2B43102293AECA257 DC70081C245/\$File/MERS-CoV-SoNG-sep2015.pdf

10. World Health Organization. Geneva: World Health Organization; 2016. WHO statement on the tenth meeting of the IHR Emergency Committee regarding MERS; 2015 Sept 3 [cited 2016 Jun 15] [about 4 screens]. Available from: www.who.int/mediacentre/news/ statements/2015/ihr-emergency-committee-mers/en/

11. World Health Organization. Geneva: Word Health Organization; 2016. What are the international health regulations and emergency committees?; 2016 Jun 10 [cited 2016 Jun 15] [about 3 screens]. Available from: www.who.int/features/qa/39/en/

\section{Copyright: (c) (i) (2) (2)}

(C) 2016 Firman et al. This article is licensed under the Creative Commons Attribution-NonCommercial-ShareAlike 4.0 International Licence, which allows others to redistribute, adapt and share this work non-commercially provided they attribute the work and any adapted version of it is distributed under the same Creative Commons licence terms. See: www.creativecommons.org/licenses/by-nc-sa/4.0/ 